\title{
PHOTOVOLTAIC BASED HYSTERETIC CONTROLLED BUCK BOOST CONVERTER WITH COUPLED INDUCTOR
}

\author{
*Vanitha.D ${ }^{1}$, M.Rathinakumar ${ }^{2}$ \\ ${ }^{*}{ }^{1}$ Research Scholar, ${ }^{2}$ Professor \\ Department of Electrical and Electronics Engineering \\ SCSVMV University,Kancheepuram,TamilNadu, India-631561 \\ *1. vanithadhanapal21@gmail.com, ${ }^{2}$ rathinamari@rediffmail.com
}

\begin{abstract}
Buck Boost Converter with Coupled Inductor (BBCCI) can be used to match the source voltage with the load voltage. This work deals with modelling and simulation of BBCCI system with hysteretic controller. The objective of this work is to improve dynamic response of closed loop BBCCI system using hysteretic controller. The closed loop controlled BBCCI systems with and without hysteretic controller are modelled, simulated and the results are analysed. The results indicate that the dynamic response is improved and current ripple is reduced using hysteretic controller. The proposed system has advantages like reduced THD, low settling time and steady state error
\end{abstract}

Key words: Photo Voltaic (PV) - Buck Boost Converter with Coupled Inductor (BBCCI) - Pulse Width Modulation (PWM) - Hysteretic controller (HC) -Upper Band (UB) -Lower Band (LB)

\section{INTRODUCTION}

A new control method using hysteretic pulse width modulation for buck boost converter is zero steady state error in output voltage and the variation of output impedance with hysteretic pulse width modulation control is presented [1]. Hysteretic control for DC to DC is given by Sato. This paper has presented dynamic performance for large load variation [2]. Hysteretic controller for all types of DC to DC converter is given by Lin. This paper has given experimental verification for buck and boost converter [3]. DC to DC switching converter and its design philosophy using hysteretic controller is given by Ang. This paper has presented optimal gate driver design [4]. Analysis of buck converter system with hysteretic control is given by Onda. This paper has presented transient response output voltage for sudden change in load. Ramp voltage is generated using RC network and the same is used for the input to the comparator. Dynamic characteristics and steady state condition for buck converter were presented. The drawback of this scheme is the reduction in switching frequency [5]. Robust hysteretic control method for switching converter is presented by Nabeshima. This paper deals with hysteretic control using extra capacitor in the comparator and higher switching frequency was achieved with good dynamic performance. This circuit has provided stable operation during switching noises [6]. Modelling of PV system with converter topology is given by Umadevi. This paper has presented DC-DC converter topology with inverter for resistive load with various irradiations [7]. Closed loop control of three port converter with high voltage gain is given by Santhi mary. This paper has presented high voltage gain for the converter with PI controller along with three port converter topology[8].FLC for PV array simulator is given by Raja. This paper is discussed with converter and controller topology for the PV system [9].

The literature [1] to [9] do not deal with comparison of PI \& Hysteretic based BBCCI systems to improve the dynamic response. This work proposes Hysteretic control to improve dynamic response and reduce the current ripple of BBCCI system.

The organization of the paper is as follows: the system description is given in section 2.Analysis of converter and controller is presented in section 3. Simulation results with PI and Hysteretic controllers are given in section 4. Hardware results are given in section 5. Work is concluded in section 6. 


\section{SYSTEM DESCRIPTION}

Block diagram of existing Buck - Boost Converter System (BBCS) is shown in figure 2.1. Fixed DC is converted into variable DC using BBCS and its output is applied to the DC load. The Control circuit generates pulses for BBCS.

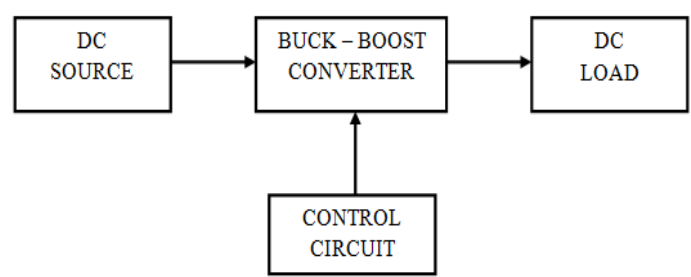

Figure 2.1. Block Diagram of existing BBCS

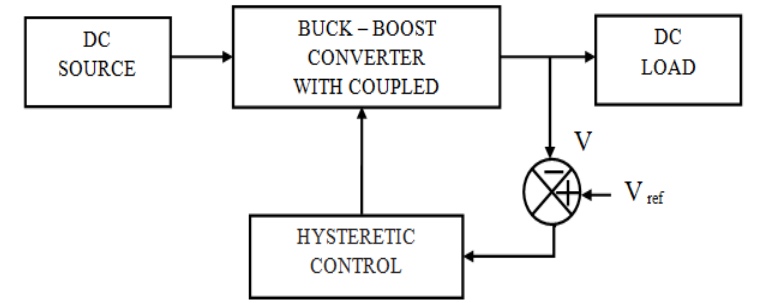

Figure 2.2 Block Diagram of proposed BBCCI

System

In proposed system, BBC is replaced by BBCCI. Output voltage is regulated using hysteretic controller as shown in Figure 2.2. The load voltage is compared with the reference voltage and the error voltage is applied to Hysteretic controller. The controller generates the updated gate pulses to regulate the output voltage of BBCCI system and limit the ripple in the output.

The principle of hysteretic control is given in Figure 2.3. Output voltage is compared with the reference voltage. The error is applied to hysteretic comparator. The output is given to the driver circuit. The driver amplifies the pulses from $5 \mathrm{~V}$ to $10 \mathrm{~V}$. The driver pulses and output voltage are shown in Figure 2.4. The pulse is applied whenever output voltage is less than $V_{r}$. The pulse is stopped whenever the output is greater than $V_{r}+V_{h}$.

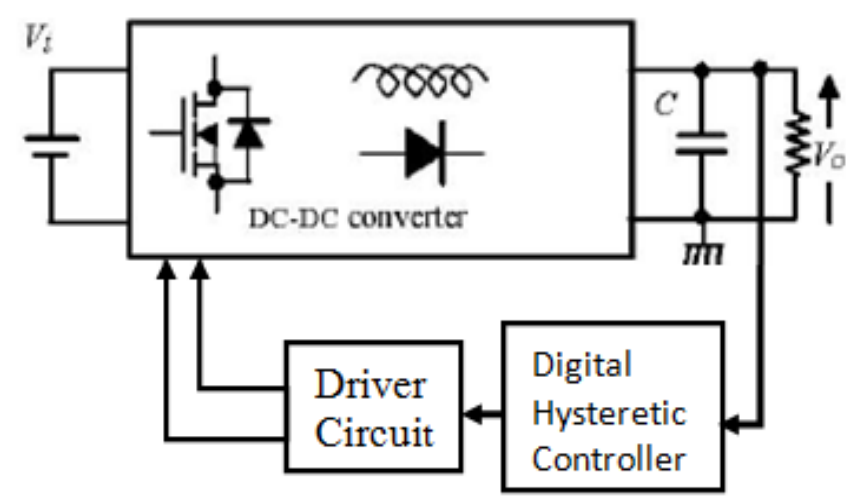

Figure 2.3 Principle of Hysteretic Control

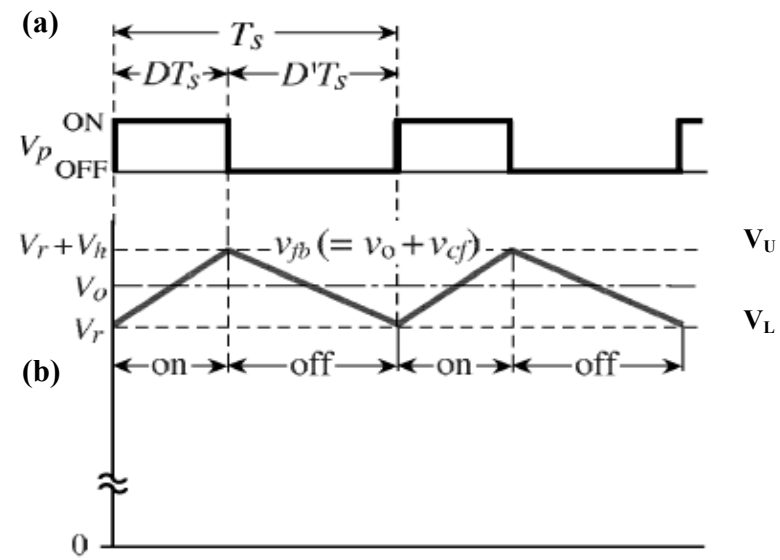

Figure 2.4 Waveforms (a) Driving Pulses

\section{ANALYSIS OF BUCK - BOOST CONVERTER}

The equations for Buck Boost converter are as follows:

Inductance (L) and Capacitance (C) are calculated using following formulae

$$
\begin{aligned}
& \mathrm{L}=\mathrm{V}_{1} \mathrm{~K} / \mathrm{f} \Delta \mathrm{I} \\
& \mathrm{C}=\mathrm{K} / 2 \mathrm{fR}_{\mathrm{L}}
\end{aligned}
$$

Where

$$
\begin{aligned}
& \mathrm{V}_{1} \text { - PV input voltage } \\
& \mathrm{K} \text { - Duty ratio } \\
& \mathrm{f} \text { - Switching frequency } \\
& \Delta \mathrm{I} \text { - change in current }
\end{aligned}
$$


$\mathrm{R}_{\mathrm{L}}$ - Load resistance

Lower and upper limit voltages for $\mathrm{HC}$ are calculated using following formulae

$$
\begin{aligned}
& \mathrm{V}_{\mathrm{L}}=\mathrm{V}_{\mathrm{r}} \\
& \mathrm{V}_{\mathrm{U}}=\mathrm{V}_{\mathrm{r}}+\mathrm{V}_{\mathrm{h}}
\end{aligned}
$$

Peak to Peak ripple voltage $V_{P}=V_{U}-V_{L}$

$\mathrm{V}_{\mathrm{r}}$ - Reference voltage

$\mathrm{V}_{\mathrm{h}}$ - Hysteretic voltage

\section{SIMULATION RESULTS}

The simulation results of open loop system, closed loop with PI and HC based BBCCI systems are presented in this section

\section{A. Open Loop BBCCI System}

Open loop BBCCI system with change in input is shown in Figure 4.1.An increase in irradiation is considered at the input. This increase will make the input voltage to increase from $12 \mathrm{~V}$ to $15 \mathrm{~V}$. The input voltage is shown in Figure 4.2. The output voltage is shown in Figure 4.3 and its value is $75 \mathrm{~V}$. The output current is shown in Figure 4.4 and its value is 1.2 A. The output power is shown in Figure 4.5 and its value is $100 \mathrm{~W}$. The increase in output power is due to the increase in input voltage.

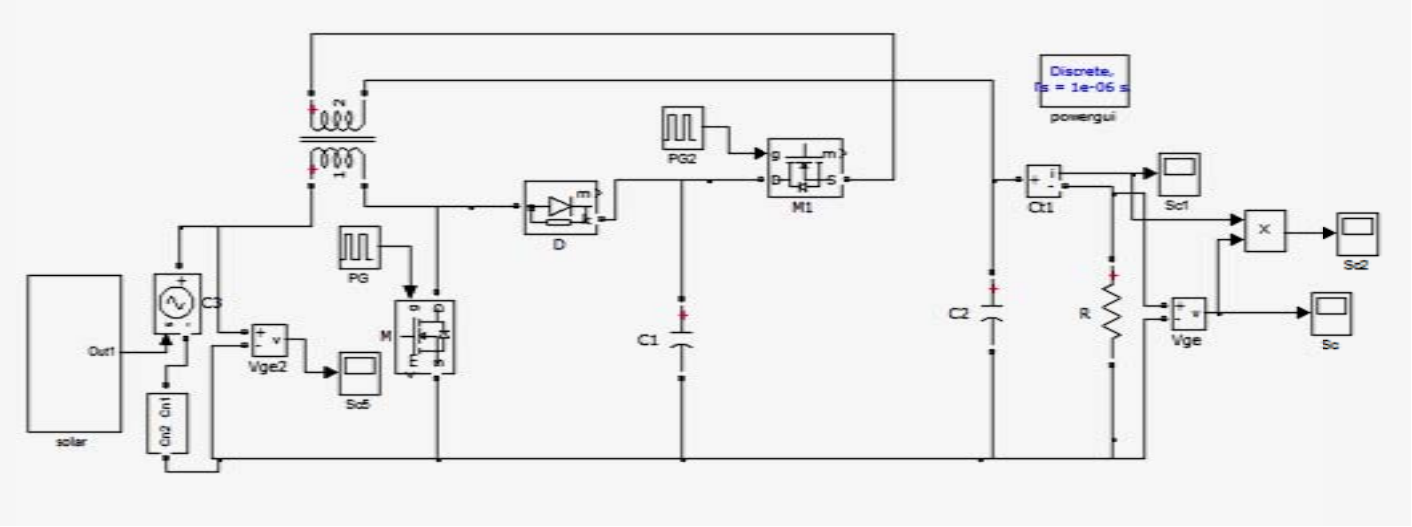

Figure 4.1. Open loop BBCCI system with change in input

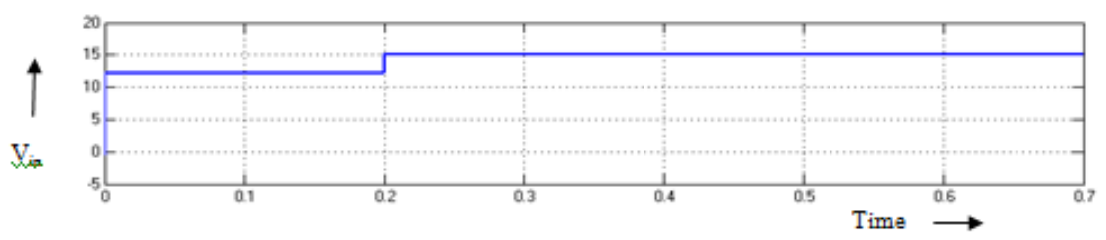

Figure 4.2 Input voltage

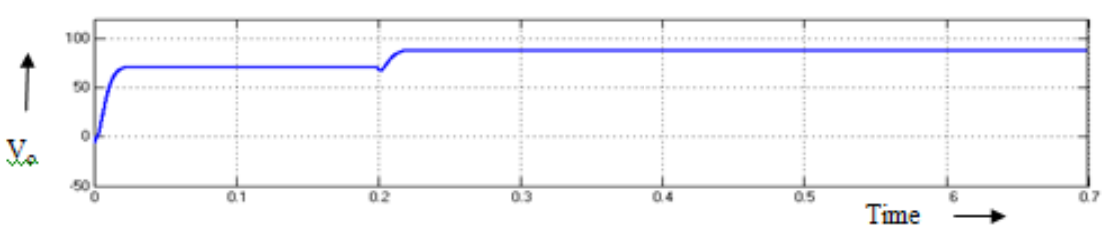

Figure 4.3 Output voltage of BBCCI 


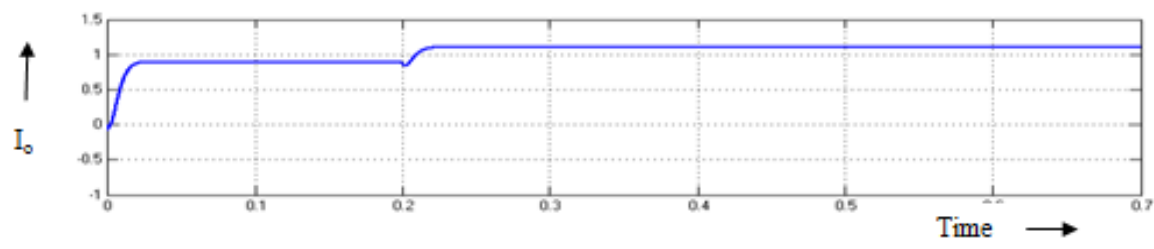

Figure 4.4 Output current of BBCCI

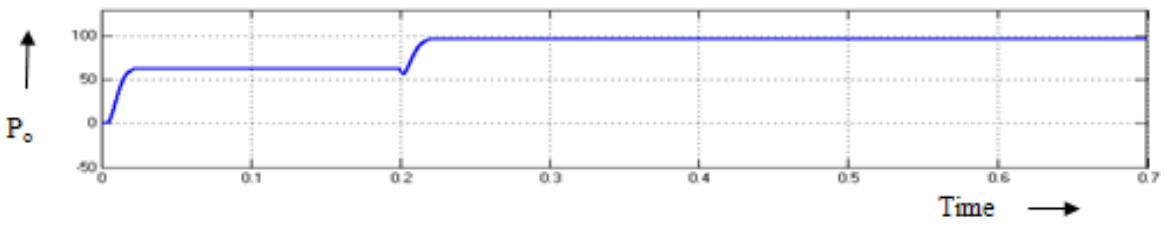

Figure 4.5 Output power of BBCCI

\section{B. Closed Loop BBCCI System with PI controller}

The BBCCI system with PI controller is shown in Figure 4.6.The output voltage is compared with reference voltage of $70 \mathrm{~V}$. The error is applied to a PI controller. The output of PI is applied to two comparators. The outputs of comparators are given to shunt and series switches. The input voltage is shown in Figure 4.7. Gate pulses are shown in figure 4.8. The output voltage is shown in Figure 4.9 and its value is $75 \mathrm{~V}$. The output current is shown in Figure 4.10 and its value is 1A. The current ripple is shown in Figure.4.11. The peak to peak ripple is $0.015 \mathrm{~A}$. The output power is shown in Figure 4.12 and its value is $75 \mathrm{~W}$.

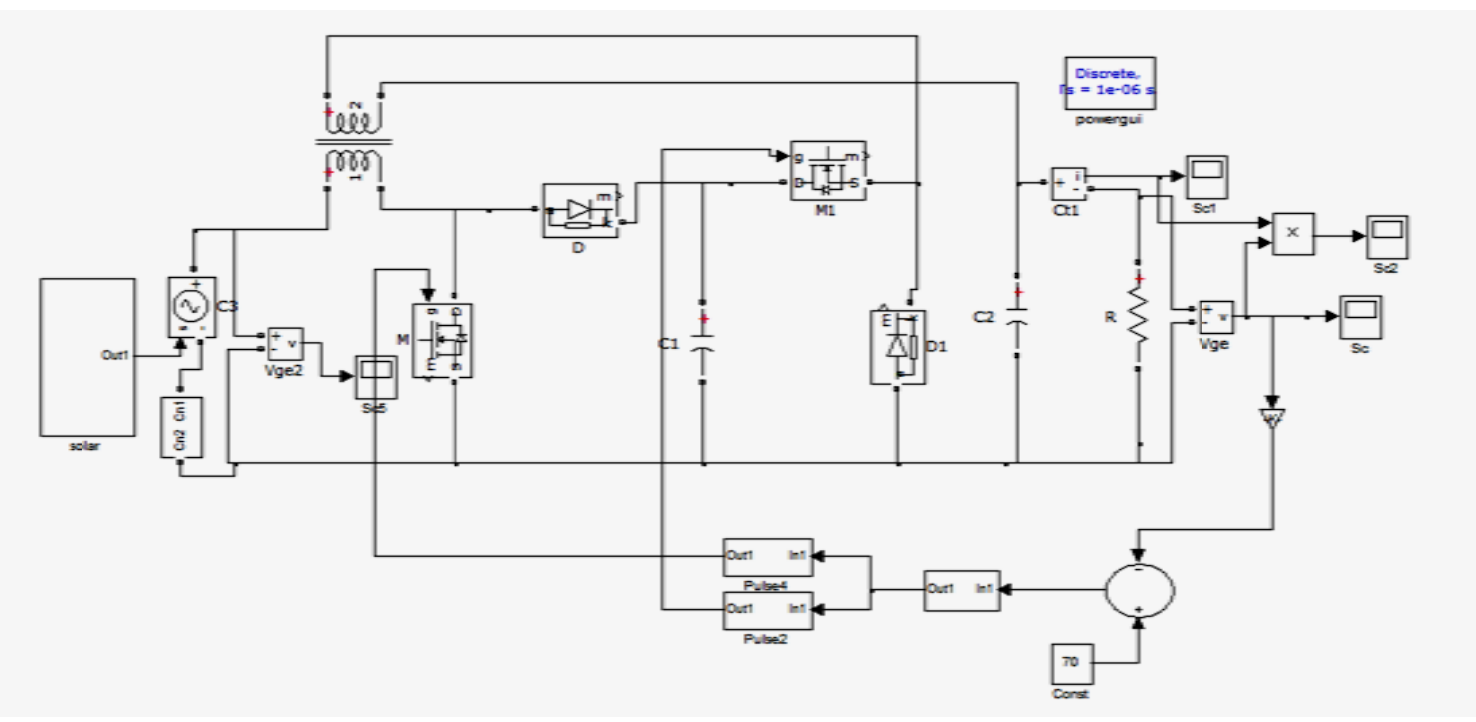

Figure 4.6 Closed Loop BBCCI system with PI controller 


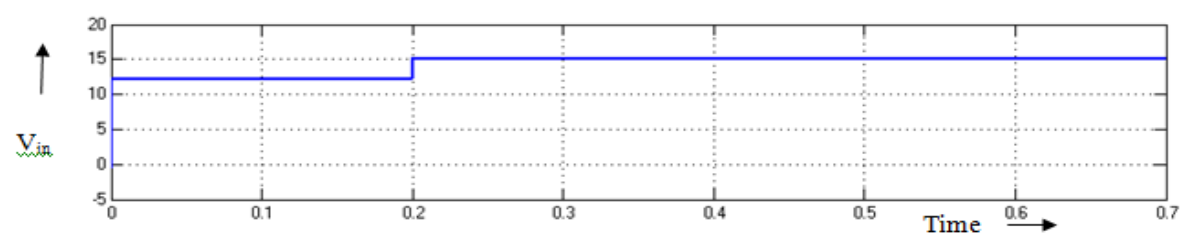

Figure 4.7 Input voltage
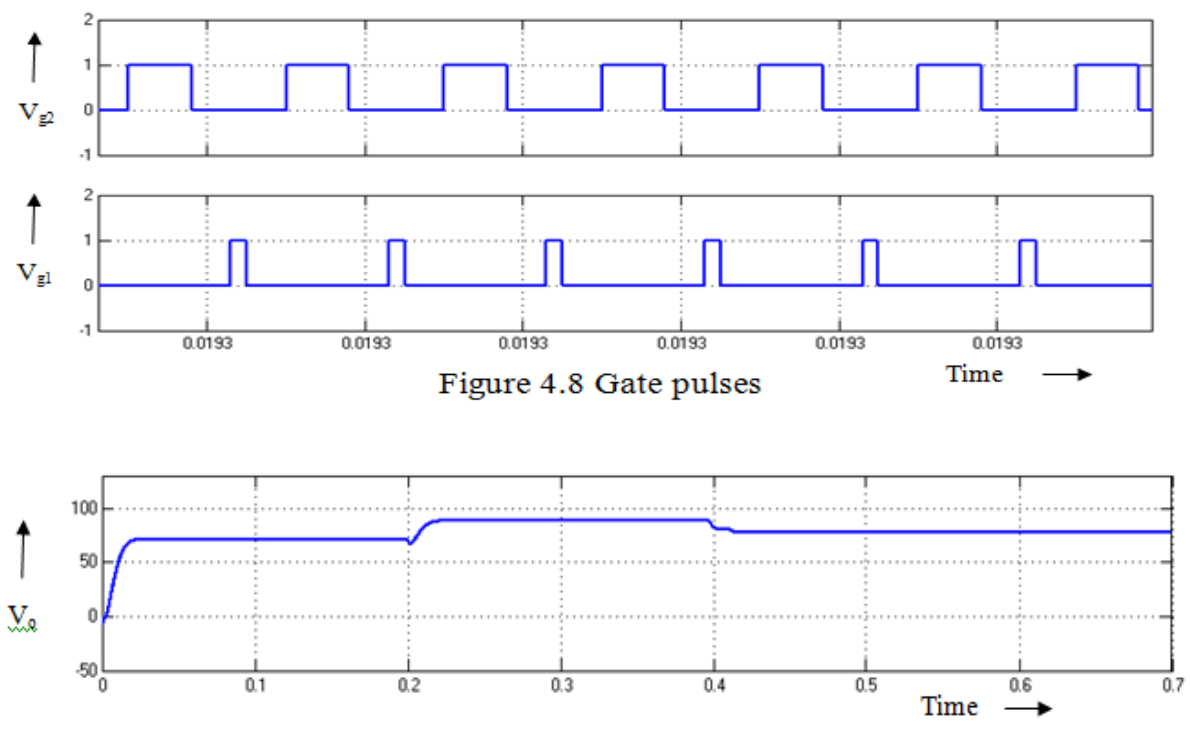

Figure 4.9 Output voltage

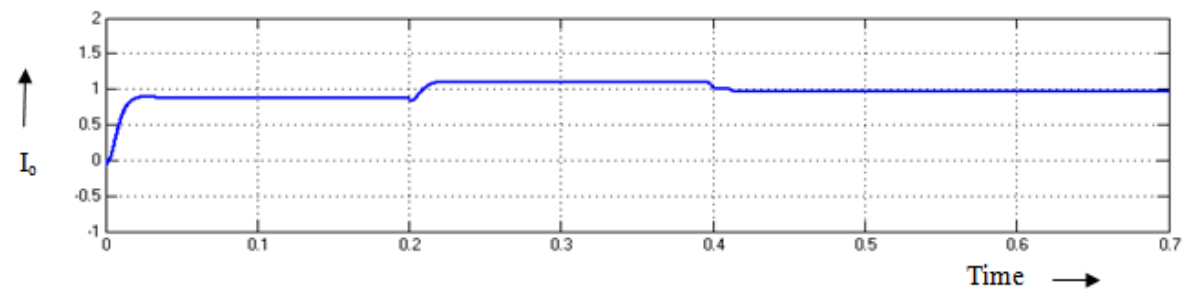

Figure 4.10 Output current

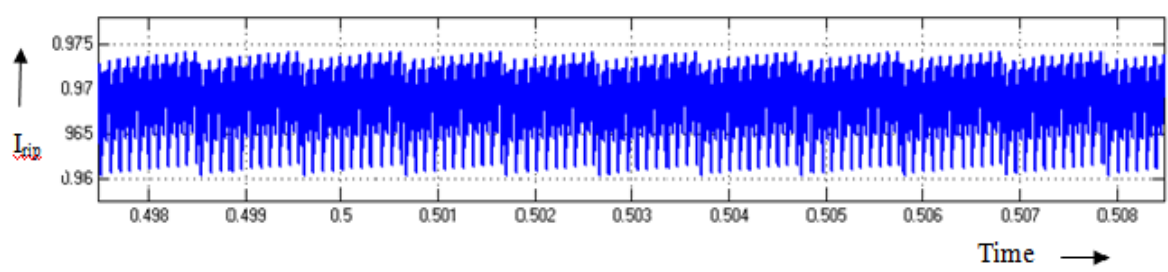

Figure 4.11 Current Ripple

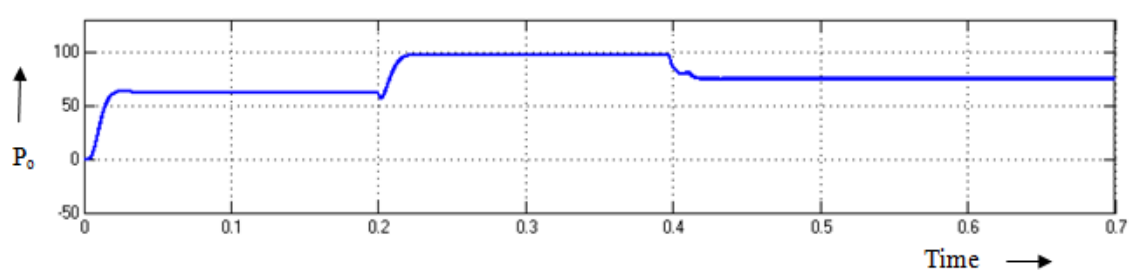

Figure 4.12 Output power of BBCCI with PIC 


\section{Closed Loop BBCCI System with HC}

The Simulink model of BBCCI system for the Buck-Boost converter is developed and it is used for simulation. The closed loop BBCCI system with hysteretic controller system is shown in Figure 4.13. The input voltage is shown in Figure 4.14 and its value is $15 \mathrm{~V}$. Gate pulses are shown in figure 4.15. The output voltage is shown in Figure 4.16 and its value is $80 \mathrm{~V}$. The output current is shown in Figure 4.17 and its value is $1 \mathrm{~A}$. The current ripple is shown in Figure 4.18. The Current ripple is reduced to 0.003A. The output power is shown in Figure. 4.19 and its value is 75 watts. The summary of simulation parameters is shown in Table- 1 .

The summary of time domain parameters is shown in Table- 2. Rise time is reduced from 0.23 to $0.21 \mathrm{Sec}$. The peak time is reduced from 0.3 to $0.25 \mathrm{sec}$., settling time is reduced from 0.42 to $0.31 \mathrm{Sec}$ and steady state error is reduced from 1.3 to 0.8 Volts using HC. Therefore dynamic response is improved using hysteretic controller. The comparison of current ripple is shown in Table - 3. It can be seen that the current ripple is reduced from 0.015 to $0.003 \mathrm{~A}$ using hysteretic controller.

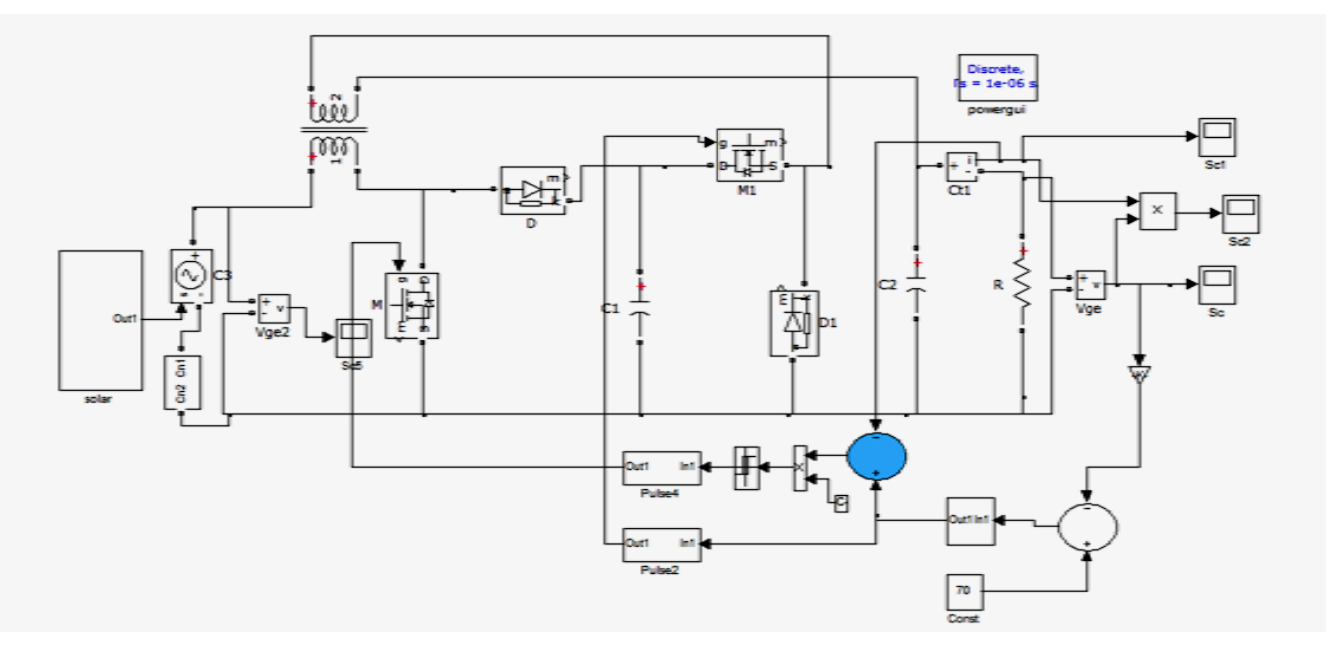

Figure 4.13 Closed loop BBCCI system With Hysteresis Controller

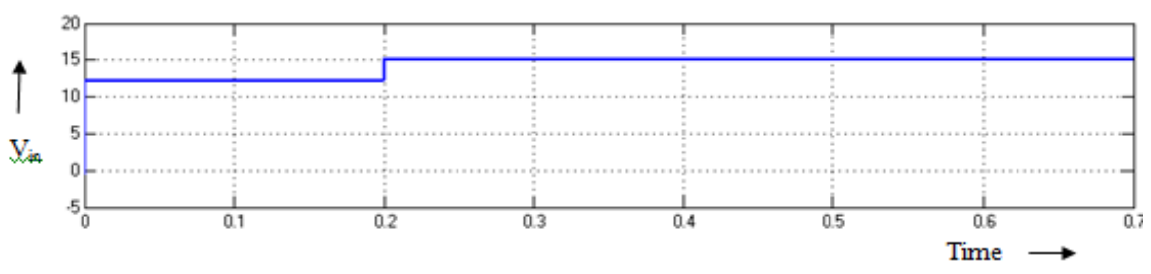

Figure 4.14 Input voltage
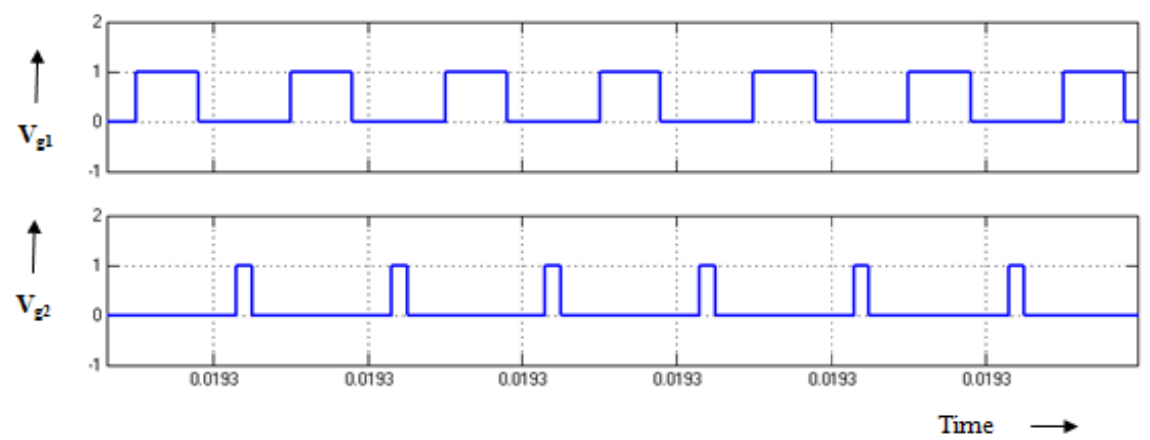

Figure 4.15 Gate pulses for $\mathrm{M}_{1}$ and $\mathrm{M}_{2}$ 


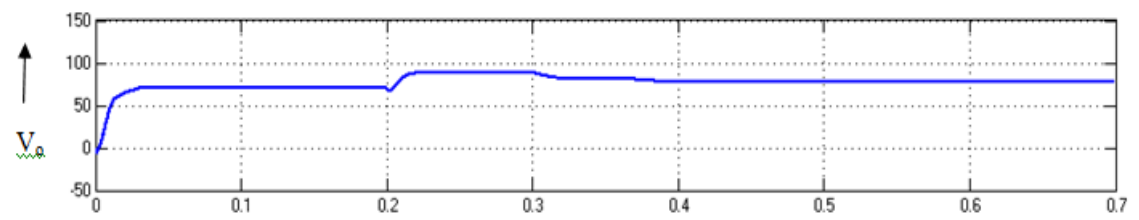

Figure 4.16 Output voltage of BBCCI with $\mathrm{HC}$

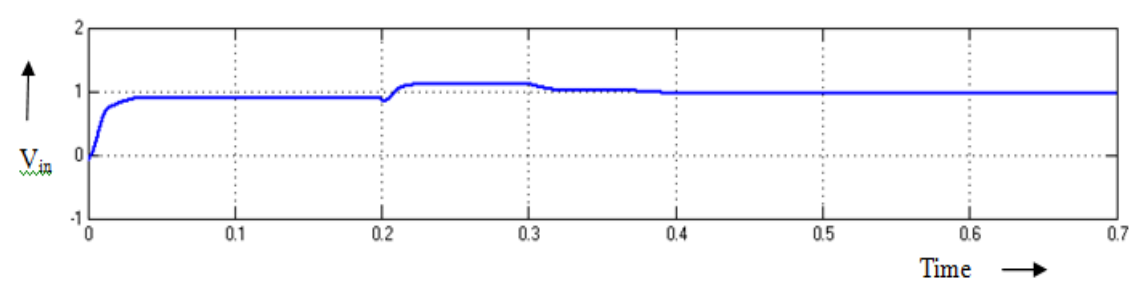

Figure 4.17 Output current of BBCCI with $\mathrm{HC}$

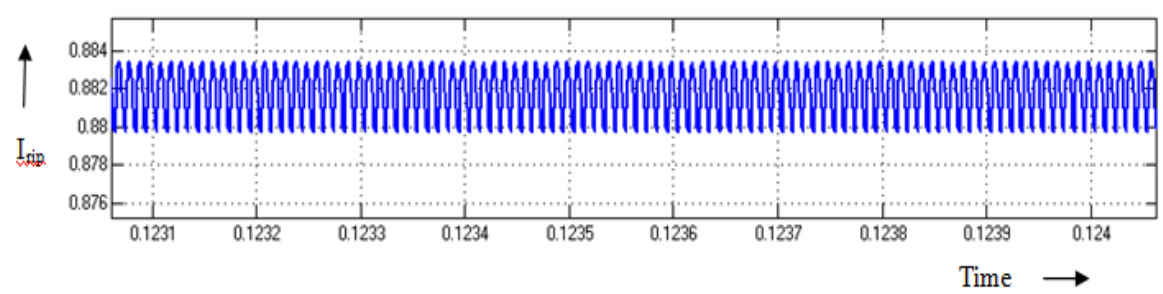

Figure 4.18 Current Ripple with HC

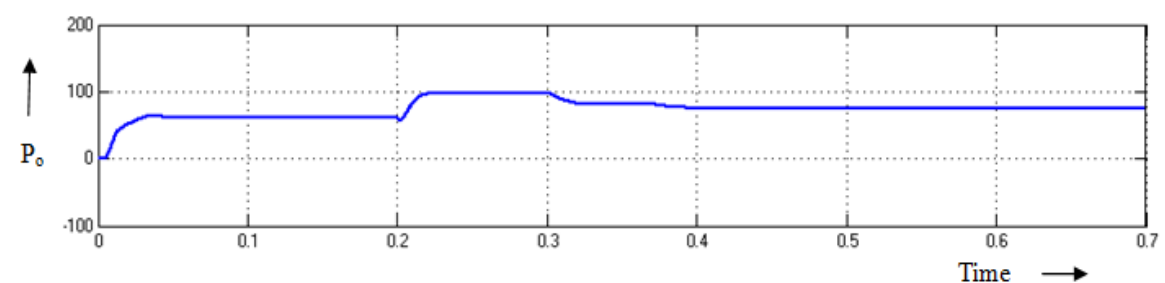

Figure 4.19 Output power of BBCCI with $\mathrm{HC}$

Table - 1 Summary of Simulation Parameters

\begin{tabular}{|c|c|}
\hline Parameters specifications & Parameters values \\
\hline $\mathrm{V}_{\text {in }}$ & $12 \mathrm{~V}$ \\
\hline $\mathrm{L}_{1}, \mathrm{~L}_{2}$ & $0.1 \mathrm{mH}$ \\
\hline $\mathrm{C}_{1}$ & $6.6 \mu \mathrm{F}$ \\
\hline $\mathrm{C}_{\mathbf{0}}$ & $50 \mu \mathrm{F}$ \\
\hline $\mathrm{UB}$ & $0.9 \mathrm{~A}$ \\
\hline $\mathrm{LB}$ & $0.6 \mathrm{~A}$ \\
\hline $\mathrm{R}_{\mathrm{L}}$ & $80 \Omega$ \\
\hline
\end{tabular}


Table-2 Summary of Time Domain Parameters

\begin{tabular}{|c|c|c|c|c|}
\hline Type of Controller & $\mathbf{t}_{\mathbf{r}}(\mathbf{s e c})$ & $\mathbf{t}_{\mathbf{p}}(\mathrm{sec})$ & $\mathbf{t}_{\mathbf{s}}(\mathrm{sec})$ & $\mathbf{E}_{\mathrm{ss}}(\mathrm{volts})$ \\
\hline PI & 0.23 & 0.3 & 0.42 & 1.3 \\
\hline Hysteresis & 0.21 & 0.25 & 0.31 & 0.8 \\
\hline
\end{tabular}

Table-3 Comparison of Current Ripple

\begin{tabular}{|c|c|}
\hline $\begin{array}{c}\text { Type of } \\
\text { Controller }\end{array}$ & $\begin{array}{c}\text { Output Current Ripple } \\
\text { (amps) }\end{array}$ \\
\hline PI controller & $\mathbf{0 . 0 1 5}$ \\
\hline With Hysteresis controller & $\mathbf{0 . 0 0 3}$ \\
\hline
\end{tabular}

\section{EXPERIMENTAL RESULTS}

The Hardware for prototype BBCCI system is fabricated and tested. Hardware snap shot for BBCCI system with Hysteretic Controller is shown in Figure 5.1. The hardware consists of PV panel, control board, rectifier board and BBCCI board. The input voltage is shown in Figure 5.2. The Switching pulses for $\mathrm{M}_{1}$ and $\mathrm{M}_{2}$ are shown in Figure 5.3. The Output voltage of BBCCI is shown in Figure 5.4. The display of output voltage is shown in Figure 5.5. The simulation results of previous section match with the experimental results presented in this section.

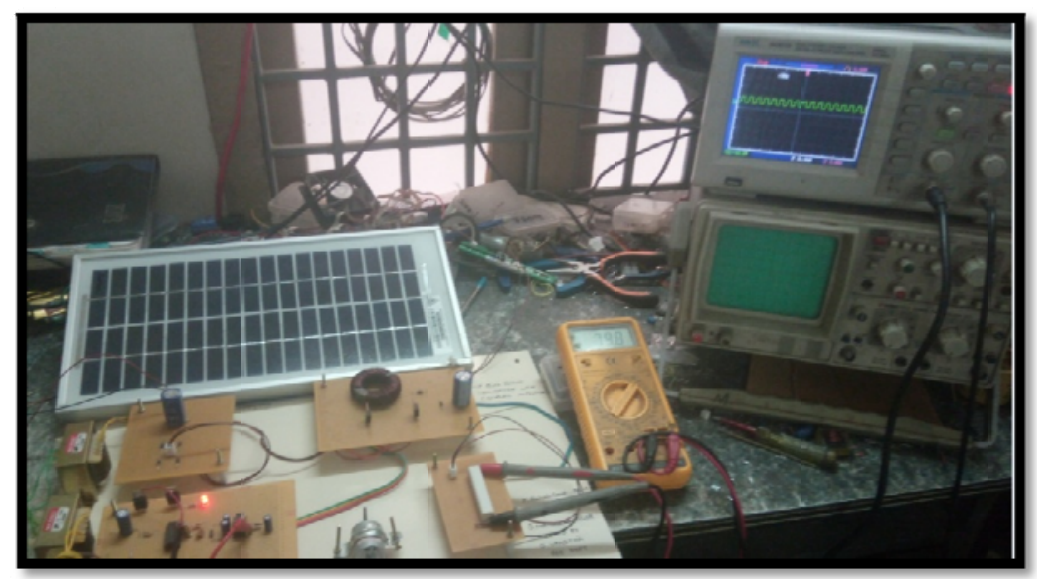

Figure 5.1 Hardware snap shot of BBCCI system

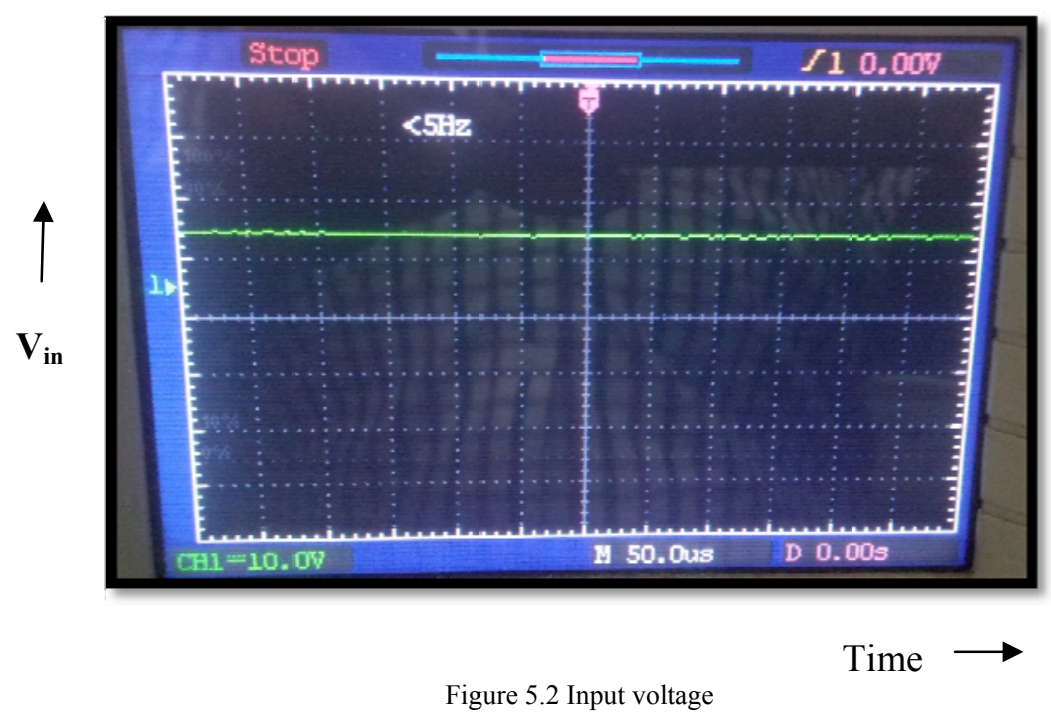



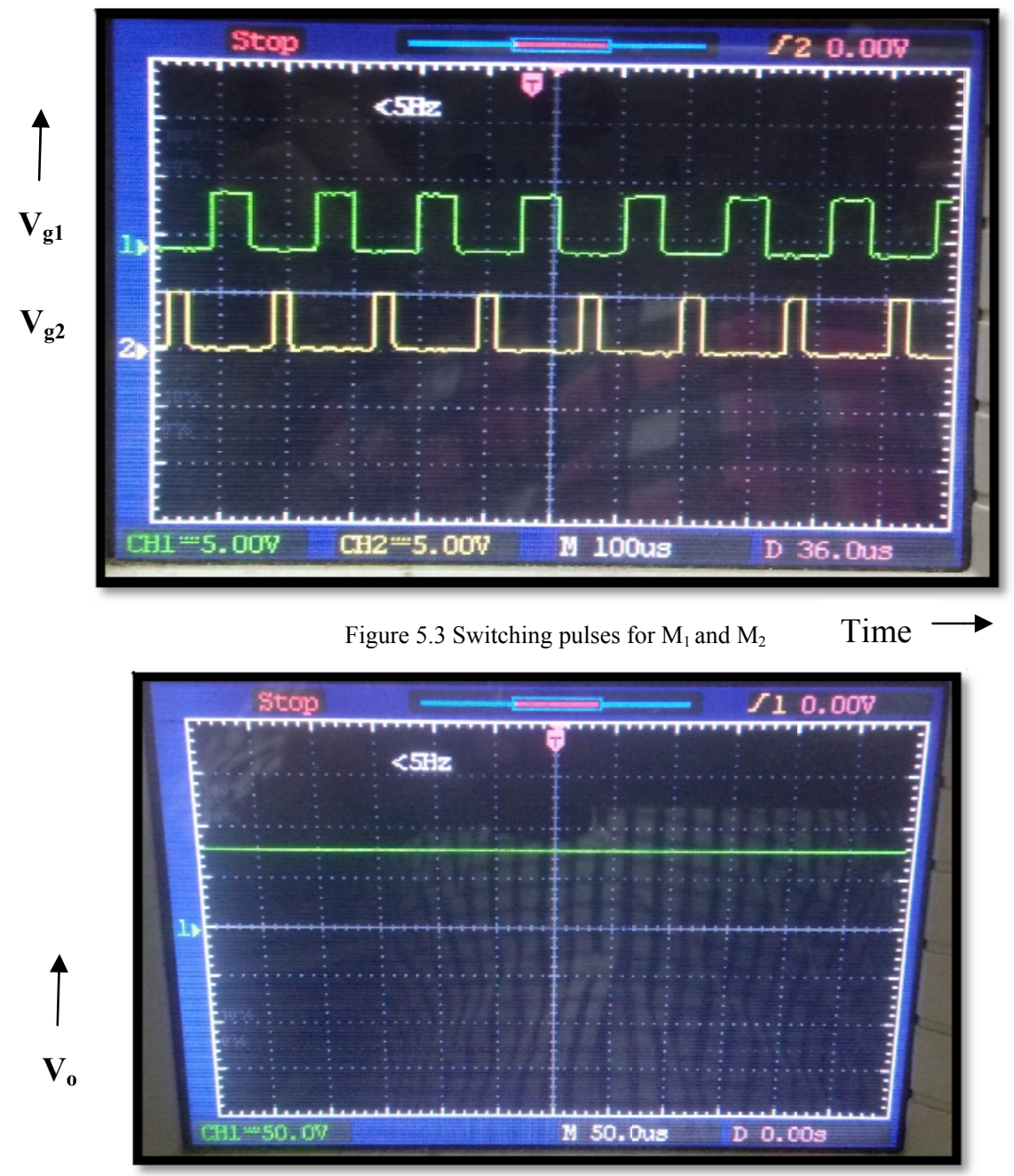

Figure 5.4 Output voltage of BBCCI system $\quad$ Time $\longrightarrow$

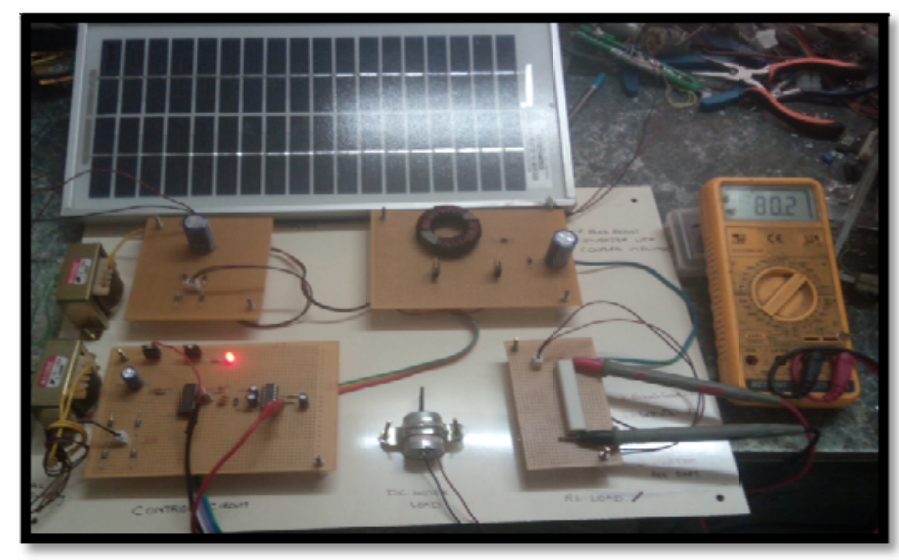

Figure 5.5 Display of Output voltage

VI. CONCLUSION

Closed loop BBCCI systems with PI and hysteretic controllers are modelled and simulated using Simulink. The settling time is reduced from 0.42 to 0.31 seconds and steady state error is reduced from $1.3 \mathrm{~V}$ to $0.8 \mathrm{~V}$ by replacing PI with HC. The current ripple is low as $0.003 \mathrm{~A}$. Hysteretic controller is used to modify the pulse width for BBCCI, so that the performance of BBCCI system is improved. The result with hysteretic controller shows better dynamic performance. The results obtained in this work are clear examples of improvement in time domain response of BBCCI system. 
The scope of present work is to model and simulate hysteretic controlled BBCCI system. Closed loop BBCCI system with proportional resonant (PR) controller will be in future. The hardware may be implemented at higher level of power.

\section{REFENCES}

[1] Takashi Nabeshimal, Terukazu Sato, Kimihiro Nishijimal and Shinnichi Yoshida ,A Novel Control Method of Boost and Buck-Boost Converters with a Hysteretic PWM Controller, tr' 2005 - Dt,'dcm ISBN 90-75815-08-1,PP 1-6

[2] Terukazu Sato, Takashi Nabeshima, Kimihiro Nishijima, Tadao Nakano, DC-DC Converters with a Novel Hysteretic PWM Controller, 2006 IEEE,PP $2729-2733$

[3] Min Lin, Takashi Nabeshima, Terukazu Sato, and Kimihiro Nishijima, Design of a New Hysteretic PWM Controller for All Types of DC-to-DC Converters, PEDS 2007, IEEE, PP 1234- 1239

[4] Jian Lv and Simon S. Ang, Design Philosophy of Hysteretic Controller for DC-DC Switching Converters,PP $1-4$

[5] Takashi Nabeshima, Ternkazu Sato, Shinichi Yoshida, Shin Chiba and Kenichi Onda, Analysis and Design Considerations of a Buck Converter with a Hysteretic PWM Controller, 35rh Annual lEEE Power Elecrronics Specialists Conference, Aachen, Gemany. 2004PP $1711-1716,2004$

[6] Min Lin, Terukazu Sato, Kimihiro Nishijima and Takashi Nabeshima, A Robust Hysteretic PWM Control Method for Switching Converters,PP $1-6$

[7] K.Umadevi, P. Nalandha, C. Chenn Kesavan, Modelling of Photovoltaic System with Converter Topology for Grid fed Operations, International Journal of Engineering and Technology, PP 2392 - 2400, Vol 6 No 5 Oct-Nov 2014

[8] Santhi Mary Antony A, Closed Loop Control Of Three Port Converter With High Voltage Gain, International Journal of Engineering and Technology, PP 1224 - 1235, Vol 7 No 4 Aug-Sep 2015

[9] R.Raja, L.Udhaya kumar, S.Rakesh kumar, Fuzzy Logic Controller For Photovoltaic Array Simulator, International Journal of Engineering and Technology, PP 1265 - 1630, Vol 5 No 2 Apr-May 2013

[10] Solar Photo Voltaic- Fundamentals, Technologies and Applications, Chetan Singh Solanki, PHI Learning Pvt. Ltd,pp 3-22, 2012

[11] Rashid, M.H Power Electronics — Circuits, Devices, and Applications. Pearson, Prentice Hall. 2004, London.

\section{AUTHOR PROFILE}

Mrs.D.Vanitha was born in Chennai, Tamilnadu ,India, on 1977. She did her diploma in Electrical and Electronics Engineering from DOTE in the year 1997. She graduated from Madras University under Electrical and Electronics Engineering in the year 2000. She obtained her post graduation in Power Electronics \& Drives from the Vinayaga Mission Deemed University in the year 2007. She has put 15 years of experience in teaching Electrical Engineering. Her areas of interest are Power Electronics, Electric Drives, Control systems and Renewable energy System. Presently she is doing Ph.D in Renewable energy sources in the Department of Electrical and Electronics Engineering SCSVMV University, Enathur, Kanchipuram, Tamilnadu, India.

Dr.M.Rathinakumar was born in Madurai, Tamilnadu, India, on 1969. He graduated from Thiyagarajar College of Engineering, affiliated to Madurai Kamarajar University under Electrical and Electronics Engineering in the year 1993. He obtained his post graduation in Power Systems from the same University in the year 1995.He obtained his Ph.D from SCSVMV University, Enathur, Kanchipuram, Tamilnadu, India in the year 2010. He has put around 20 years of experience in teaching Electrical Engineering. His areas of interest are Power systems, Power Quality, Power System Operation and Control. Presently he is working as Professor and Head in the Department of Electrical and Electronics Engineering SCSVMV University, Enathur, Kanchipuram, Tamilnadu, India. 